\title{
Diagnosis and Treatment of Penile Fractures: A Single Center Series
}

\author{
Mehmet Harbiyeli1 ${ }^{1}$, Hassan Abol-Enein'2, Truls Erik Bjerklund Johansen ${ }^{3 *}$ \\ ${ }^{1}$ Oslo University Hospital, Oslo, Norway \\ ${ }^{2}$ Urology \& Nephrology Center, Mansoura University, Mansoura, Egypt \\ ${ }^{3}$ Urology Department, University of Oslo, Oslo University Hospital, Oslo, Norway \\ Email:*tebj@medisin.uio.no
}

How to cite this paper: Harbiyeli, M., Abol-Enein, H. and Johansen, T.E.B. (2017) Diagnosis and Treatment of Penile Fractures: A Single Center Series. Open Journal of Urology, 7, 31-39. https://doi.org/10.4236/oju.2017.72005

Received: January 2, 2017

Accepted: January 22, 2017

Published: January 25, 2017

Copyright $\odot 2017$ by authors and Scientific Research Publishing Inc. This work is licensed under the Creative Commons Attribution International License (CC BY 4.0).

http://creativecommons.org/licenses/by/4.0/ (c) (i) Open Access

\begin{abstract}
Objectives: The aim of this study is to review the diagnostic work-up, treatment methods and outcomes in patients treated for penile fractures. Methods: Thirty-one patients were treated for penile fracture during the period 2006-2014. Data were retrieved from patients' journals and analyzed retrospectively. Follow-up data were available for 23 patients. Results: Twenty-eight patients (90\%) experienced immediate pain at incidence; 29 (94\%) experienced immediate swelling; 23 (74\%) heard a cracking sound; 20 (65\%) observed a blue discoloration immediately afterwards and 20 (65\%) got immediate detumescence. Magnetic Resonance Imaging was used preoperatively in 10 patients and demonstrated the side and localization of the rupture in tunica albuginea in all cases. A longitudinal incision over the suspected site of the rupture was used in 20 patients and a sub-coronal de-gloving incision of the penile skin was used in 10 patients. The average operation time with longitudinal incision method and de-gloving was 43 minutes and 57 minutes, respectively. Short term complications were seen in four patients and long term complications were seen in 14 patients of which deviation of penis during erection was most common. Conclusions: Immediate pain, swelling and hearing a cracking sound are predominant features in the history of patients with penile fracture. Magnetic Resonance Imaging is recommended for localizing the rupture site. A longitudinal incision over the rupture site means significantly shorter operation time than de-gloving.
\end{abstract}

\section{Keywords}

Clinical Presentation, Imaging, Magnetic Resonance Imaging, Operative Technique, Penile Fracture

\section{Introduction}

Penile fracture is defined as a rupture of tunica albuginea caused by blunt trauma 
during erection. It is a rare urological emergency and immediate surgical repair is recommended to obtain optimal functional outcome and avoid complications [1] [2].

The erect penis is at risk of fracture since the thickness of tunica albuginea, which is ca $2 \mathrm{~mm}$ when the penis is flaccid, is reduced to $0.25 \mathrm{~mm}$ when the penis is erect [3] [4]. Trauma during sexual intercourse is the most common cause but forceful manipulation of the penis to achieve detumescence also occurs [5].

Immediate surgery is recommended and preoperative localization of the rupture site is important for the extent of the surgical dissection. However, most patient series are small and the value of the different diagnostic tools is uncertain. The role of MRI to accurately localize the fracture site is of special interest [6]. The most common surgical approaches are longitudinal incision over the rupture site and sub-coronal de-gloving incision, but the importance of the surgical approach for the operation time and outcome is poorly described.

The objective of the present study was to review patients' history, findings at clinical examination and imaging as well as treatment and outcome in patients admitted with suspected penile fracture to the Department of Urology at Oslo University Hospital during the recent ten-year period.

\section{Methods}

From 2006 to 2014, 31 patients were referred with suspected penile fracture. Patients were identified in our clinical database by the following ICD10 codes: N48.9 (Nonspecific penile disorders); N48.8 (Other specified penile disorders); S30.2, S37.9 (Injury of non-specified pelvic organ); S38.0 (Injury of external genital organs) and the following NCSP codes (The NOMESCO Classification of Surgical Procedures): KGH00 (Suture of penis); KGA96 (Other explorations or incisions of the penis). Operation notes by the urologist, imaging reports (MRI, Ultrasound), clinicians' notes and the notes of nurses were reviewed.

Thirty patients were operated and follow-up information was provided for 23 patients of whom 18 were contacted by phone and filled in a questionnaire. Patients were asked about symptoms and whether the incident occurred during sexual intercourse or not. We also asked about postoperative complications such as penile deviation during erection, difficulty passing urine and reduced erectile function. The following variables were analyzed: age; medical history; symptoms and signs; findings at physical examination; time of day; diagnostic tests used; localization and size of any rupture of penile structures; time from trauma to operation; operative method; duration of operation; postoperative hospitalization period (days) and complications.The study was approved by the local ethical committee.Informed consent was obtained from all patients who took part in the telephone interviews.

\section{Results}

Patients. The average age was $39.9(19$ - 69) years, median 38.5. One patient suffered from penile deviation before the injury. Three patients were influenced by 
alcohol. One was heroin addicted and one used cannabis.

Timing. The majority of the incidents occurred during night time or early morning (22:00-09:00) 77\% while the daytime incidence rate (09:00-22:00) was $23 \%$.

Trauma history. The fracture occurred during sexual intercourse in 25 patients $(80 \%)$ and with erect penis without intercourse in $4(13 \%)$. Trauma to flaccid penis was reported in $2(6 \%)$ and one patient could not report if the penis was erected or not (3\%). Only eight patients (26\%) gave a detailed history of the incidence with woman reported to have been on top in 2 cases; pushing the erect penis down to achieve detumescence in 2; changing intercourse position in 1 ; rolling over in bed1andtrauma from a stapler 1.

Initial symptoms and clinical findings. Twenty-eight patients (90\%) reported sudden pain; 29 (94\%) reported immediate swelling; 23 (74\%) heard a cracking sound; 20 (65\%) experienced detumescence and 20 (65\%) saw a blue discoloration. Five patients (17\%) also had a urethral injury of which 4 presented with macroscopic hematuria. All patients with hematuria had urethra injury.

Localization of rupture. Localization of the rupture according to the operation reports were available for 24 patients: distal $1 / 3$ of penis in 3 (10\%) patients; middle $1 / 3$ in 8 (27\%) patients and proximal 1/3 in 13 (43\%) patients (Figure 1 ). Twenty-eight patients had a unilateral rupture of corpus cavernosum, 4 of them with concomitant rupture of the urethra. Two patients had bilateral rupture of corpus cavernosum, one of them with a concomitant urethral rupture.

Radiological findings. MRI was used preoperatively in 10 patients, of which 9 were done after 2010. MRI confirmed the diagnosis of penile fracture in all cases and demonstrated the side and the exact localization of the rupture. MRI showed unilateral cavernosum injury in two patients where the operation revealed bilateral cavernosum injury in one and an accompanying urethral injury in the other. MRI reported both cavernosum and spongiosum injury in one patient, but operation revealed only a cavernosum injury. Ultrasound (US) examination was used only once and the site of the rupture was localized accurately.

Treatment. Thirty patients were operated and one was treated conservatively. The patient that was not operated presented with a cracking sound only without

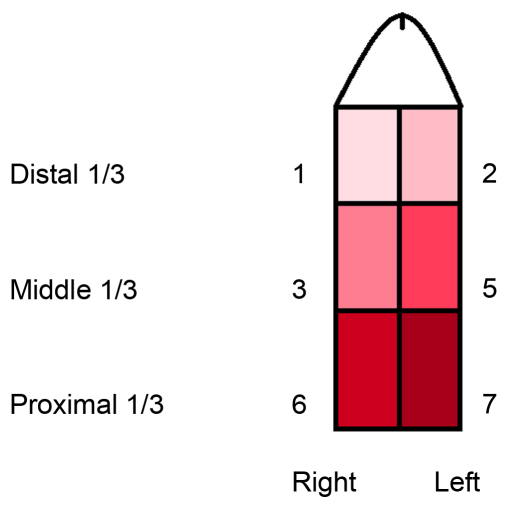

Figure 1. Longitudinal section of penis illustrating position and side of penile fractures. 
sudden pain, swelling, detumescence or blue discoloration. Twenty-seven patients were operated within 24 hours after the incident, two patients were operated within 48 hours and one patient was operated 13 days after the incident due to delayed referral. Fourteen patients got a urethral catheter either before or during the operation. The catheter was removed the next day in nine patients. Five patients with urethral injury kept the catheter for 3 - 14 days. Eighteen patients were given antibiotic prophylaxis. Ampicillin was most commonly used.

Surgical technique. Two different approaches were used. A longitudinal incision over the rupture site in tunica albuginea was used in 20 patients and a sub-coronal de-gloving incision was used in 10 patients. Four patients operated with de-gloving were circumcised previously and 4 were circumcised during the present surgery. The size of the rupture varied from $8 \mathrm{~mm}$ to $4 \mathrm{~cm}$ in length. Absorbable sutures were used in 17 patients and non-absorbable sutures were used in 6 patients. For the other patients, the suture type was not reported. The average duration of surgery was 49 minutes for all operations, 43 minutes for longitudinal incision and 58 minutes for de-gloving, respectively. Details are given in Table 1.

Hospitalization period. The average hospitalization period was 1, 6 days (1 - 5 days). Twenty patients stayed one day. Reasons for a prolonged hospitalization were bilateral injury in one patient ( 3 days) and concomitant injury of urethra in one patient ( 2 and 5 days).

Follow-up. Information was available for 23 of the 31 patients. Five patients came for outpatient visits 1 - 6 months after the operation. Eighteen patients underwent a telephone interview in February 2016, thus giving an average observation time of 6 years ( 3 - 10 years). Four patients (13\%) experienced short term complications like wound infection (2) and hematoma in scrotum (2). On latest follow-up 10 patients (32\%) complained of deviation of erect penis, one of which reported difficulties during intercourse, three patients (10\%) complained of problems to obtain or maintain erection and one complained of weak flow due to a urethral stricture. Details are displayed in Table 2.

One patient had ruptures of both c. cavernosa and a complete rupture of the urethra. He was operated within 24 hours. On outpatient visit after three months,

Table 1. Mean operation time and range in minutes in patients with penile fracture presented according to extent of injury and surgical approach.

\begin{tabular}{|c|c|c|c|}
\hline Extent of injury & Longitudinal incision & De-glowing incision & Total \\
\hline $\begin{array}{c}\text { Corpus cavernosum, } \\
\text { unilateral }\end{array}$ & $\begin{array}{c}\mathrm{N}=15 \\
36(20-71) \text { minutes }\end{array}$ & $\begin{array}{c}\mathrm{N}=9 \\
59(37-89) \text { minutes }\end{array}$ & $\begin{array}{c}\mathrm{N}=24 \\
44(20-89) \text { minutes }\end{array}$ \\
\hline $\begin{array}{c}\text { Corpus cavernosum, } \\
\text { bilateral }\end{array}$ & $\begin{array}{c}\mathrm{N}=1 \\
77 \text { minutes }\end{array}$ & 0 & $\begin{array}{c}\mathrm{N}=1 \\
77 \text { minutes }\end{array}$ \\
\hline $\begin{array}{l}\text { Corpus cavernosum, } \\
\text { unilateral + urethra }\end{array}$ & $\begin{array}{c}\mathrm{N}=3 \\
62(35-83) \text { minutes }\end{array}$ & $\begin{array}{c}\mathrm{N}=1 \\
49 \text { minutes }\end{array}$ & $\begin{array}{c}\mathrm{N}=4 \\
59(35-83) \text { minutes }\end{array}$ \\
\hline $\begin{array}{l}\text { Corpus cavernosum, } \\
\text { bilateral + urethra }\end{array}$ & $\begin{array}{c}\mathrm{N}=1 \\
70 \text { minutes }\end{array}$ & 0 & $\begin{array}{c}\mathrm{N}=1 \\
70 \text { minutes }\end{array}$ \\
\hline Total & $\begin{array}{c}\mathrm{N}=20 \\
43(20-83) \text { minutes }\end{array}$ & $\begin{array}{c}\mathrm{N}=10 \\
58(37-89) \text { minutes }\end{array}$ & $\begin{array}{c}\mathrm{N}=30 \\
49(20-89) \text { minutes }\end{array}$ \\
\hline
\end{tabular}


he complained of deviation and some pain during erection. Four months after the first incident he suffered a second penile fracture with incomplete urethral rupture at the same localization and was operated again. Three months after the second operation he presented with a urethral stricture and was treated with internal urethrotomy. Due to recurrence of stricture an open urethroplasty is planned.

\section{Discussion}

Penile injuries are uncommon because of the relatively protected location and high mobility of the flaccid penis. An erect penis is more vulnerable and is considered a prerequisite for rupture of tunica albuginea. Penile fracture is the most common traumatic injury to the penis [6] [7].

Several authors argue that a penile fracture can be diagnosed by a characteristic history and clinical findings [5] [8] [9]. A hematoma and ecchymosis, the so-called "eggplant" or "aubergine" sign is a typical finding (Figure 2(a)). Due to the mass effect of the hematoma the penis often deviates away from the site of the tear. On palpation the localized blood clot can be felt movable over the rupture site and this finding is described as "the rolling sign".

Table 2. Complications in 30 patients operated for penile fracture. Fifteen patients (50\%) had one or more complications.

\begin{tabular}{lc}
\hline Complications & $\mathrm{N}(\%)$ \\
\hline No follow-up data & $8(26 \%)$ \\
Wound infection & $2(7 \%)$ \\
Hematoma in scrotum & $2(7 \%)$ \\
Penile deviation during erection & $10(32 \%)$ \\
Difficulties to obtain or maintain erection to completion of intercourse & $3(10 \%)$ \\
Excessive and nonsymmetrical skin at prepuce & $1(3 \%)$ \\
Urethral stricture & $1(3 \%)$ \\
\hline
\end{tabular}

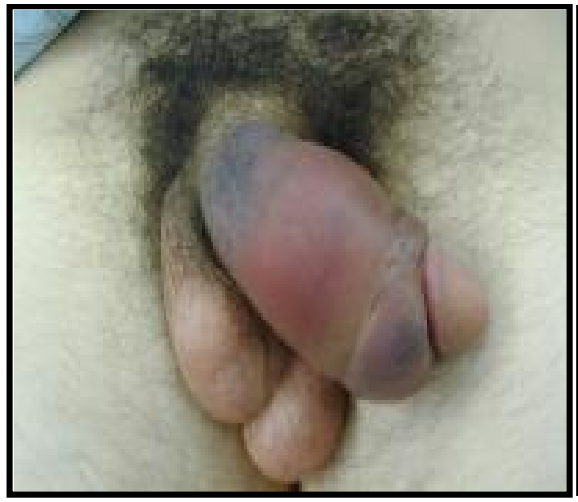

(a)

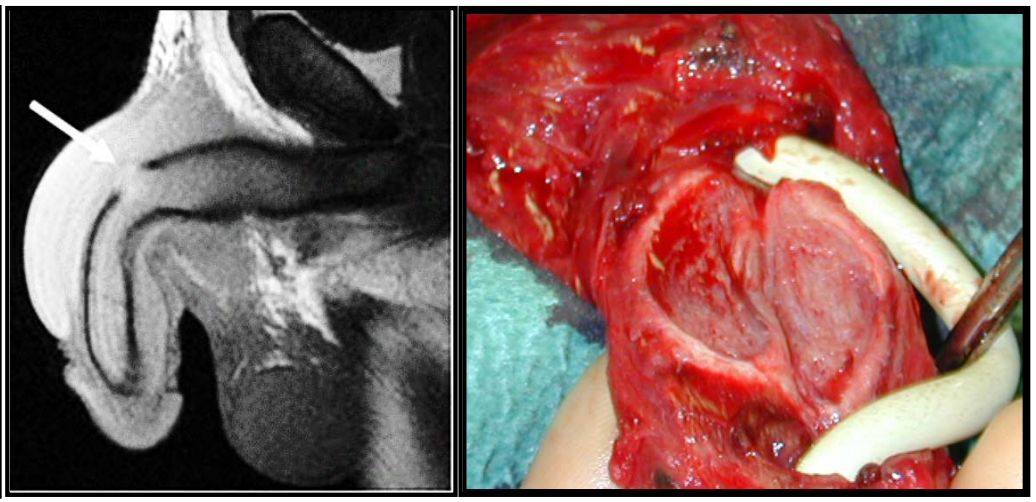

(b) (c)

Figure 2. (a) Penile fracture, showing swelling, ecchymosis and deformity (the so-called "eggplant" or "aubergine" sign). (b) Magnetic resonance imaging of penis in sagittal plane. The arrow points at the rupture in corpus cavernosum with surrounding hematoma. (c) Bilateral fracture of corporas cavernosa and total rupture of urethra. A urine catheter has beens inserted. 
MRI was used for the 10 most recent patients in our series and was found to be a valuable diagnostic tool (Figure 2(b)). MRI is considered superior to other imaging methods due to its excellent ability to visualize all penile structures [3], but excluding a penile fracture with a negative MRI is still uncertain [10]. MRI may also exclude important differential diagnoses like rupture of the circumflex or dorsal vein of the penis [3]. However, costs and availability still limits the use of MRI in the diagnostic work-up of penile fractures [11]. Although ultrasound is a cost-effective and easily available diagnostic method this modality was not routinely used in our patients.

Concomitant urethral injury is reported in $10 \%-33 \%$ of penile fractures and patients often present with hematuria and voiding difficulties [12], but absence of these symptoms does not exclude urethral injury [13]. In our series a urethral injury was seen at operation in one patient who didn't have hematuria at presentation. Patients with bilateral c. cavernosum rupture have a higher risk of urethral injury [14] [15] [16] [17] (Figure 2(c)). In our study, two patients suffered from bilateral c. cavernosum injury and one of them also had an urethral injury (50\%).

A sub-coronal de-gloving incision of the penile skin and a longitudinal penoscrotal incision over the rupture site were the only approaches used in our series. Other alternatives are inguinoscrotal, lateral and suprapubic incisions [18]. With a sub-coronalde-gloving incision, a larger part of the penis is explored [5]. However, this approach requires longer operative time and carries a risk of damaging blood vessels and nerves, with subsequent skin necrosis and wound infection [19]. The risk increases if a circumcision is not performed. In a prospective observational study, Mahapatra et al. found distal necrosis in two out of three cases where a de-gloving incision was used without performing a circumcision [20]. However, Phillips et al. could not show any difference in complication rates between peno-scrotal and de-gloving approach [17]. Our patient series did not allow for a valid assessment of differences in complication rates and long-term outcomes between the two approaches, but de-gloving meant longer operation time and was more often followed by circumcision and an increased risk of prepuce complications. In our department, each urologist only operate one case of penile fracture every second year. We believe the rarity of this condition is an argument for using the safest approach.

Thirteen patients $(42 \%)$ in our series reported deviation or reduced erection on the latest follow-up assessment. The figures are comparable to those of Swanson et al. who reported almost $35 \%$ weakened erectile function after operative treatment in a series of 30 patients [21]. Other authors report rates of 0 and $11 \%$ in groups of 10 and 42 patients, respectively [1] [2]. De Giorgi et al. underline the importance of immediate surgical repair to avoid complications and ensure optimal functional outcome. [1] Two patients in our series were operated as late as 42 hours and 13 days after the incident and both are suffering from reduced erectile function. One patient who was operated for his second penile fracture and urethral stricture also complains of weakened erectile function. 
Conservative treatment means loss of erectile function in $10 \%-30 \%$ of cases due to fibrous tissue formation [22] [23] [24] [25]. As a rule, penile fracture should be operated as an emergency [1] [2]. Our patients were advised to be abstinent from sexual intercourse for 2 - 6 weeks. One patient suffered a second penile fracture at the same localization 4 months after the first injury. No information about the risk of re-rupture at the same localization could be found in the papers reviewed for the present study. Patients are advised not to have vigorous intercourse for $1-2$ months after the operation but there is no consensus about the period of abstinence [26] [27] [28].

Our study is restricted by its retrospective approach and the fact that follow-up information was available for 23 of 31 patients only. Cognitive differences between patients and use of alcohol and narcotics suggest that patient reported results must be considered with caution.

\section{Conclusions}

The main findings in our study were that all patients with penile rupture presented with classical symptoms, MR showed the rupture site correctly and the average operation time was shorter when a longitudinal incision was used as compared to de-gloving. Thirty-two percent of patients complained of deviation of erect penis and $10 \%$ reported reduced erectile function on follow-up assessment.

While surgery without preoperative imaging would still be a reasonable approach for the experienced surgeon, MRI adds valuable information about the exact site of the lesion. Once diagnosis is established and the rupture site is detected we recommend operation with a longitudinal incision over the rupture site rather than de-gloving. Patients should be informed about the risk of deviation of erect penis after surgery.

\section{Acknowledgements}

The study was approved by the local ethical committee.

\section{References}

[1] De Giorgi, G., Luciani, L.G., Valotto, C., et al. (2005) Early Surgical Repair of Penile Fractures: Our Experience. Archivio Italiano di Urologia e Andrologia, 77, 103-105.

[2] Reis, L.O., Cartapatti, M,, Marmiroli, R., et al. (2014) Mechanisms Predisposing Penile Fracture and Long-Term Outcomes on Erectile and Voiding Functions. Advances in Urology, 2014, Article ID: 768158.

[3] Antonini, G., Vicini, P., Sansalone, S., et al. (2014) Penile Fracture: Penoscrotal Approach with Degloving of Penis after Magnetic Resonance Imaging (MRI). ArchivioItaliano di Urologia e Andrologia, 86, 1. https://doi.org/10.4081/aiua.2014.1.39

[4] Ei-Bahnasawy, M.S. and Gomha, M.A. (2000) Penile Fractures: The Successful Outcome of Immediate Surgical Intervention. International Journal of Impotence Research, 12, 273-277. https://doi.org/10.1038/sj.ijir.3900571

[5] Moslemi, M.K. (2013) Evaluation of Epidemiology, Concomitant Urethral Disruption and Seasonal Variation of Penile Fracture: A Report of 86 Cases. Canadian Urological Association Journal, 7, e572-e575. https://doi.org/10.5489/cuaj.179 
[6] De Lucchi, R., Rizzo, L., Rubino, A. and Tola, E. (2004) Magnetic Resonance Diagnosis of Traumatic Penile Fracture. La Radiologia Medica, 107, 234-240.

[7] Kurkar, A., Elderwy, A.A. and Orabi, H. (2014) False Fracture of the Penis: Different Pathology but Similar Clinical Presentation and Management. Urology Annals, 6, No. 1.

[8] Bali, R.S., Rashid, A., Mushtaque, M., et al. (2013) Penile Fracture: Experience from a Third World Country. Advances in Urology, 2013, Article ID: 708362.

[9] Zargooshi, J. (2000) Penile Fracture in Kermanshah Iran: Report of 172 Cases. The Journal of Urology, 164, 364-366. https://doi.org/10.1016/S0022-5347(05)67361-2

[10] Kirkham, A. (2012) MRI of the Penis. The British Journal of Radiology, 85, S86-S93. https://doi.org/10.1259/bjr/63301362

[11] Buyukkaya, R., Buyukkaya, A. and Ozturk, B. (2014) Role of Ultrasonography with Color-Doppler in the Emergency Diagnosis of Acute Penile Fracture: A Case Report. Medical Ultrasonography, 16, 67-69. https://doi.org/10.11152/mu.2014.2066.161.rb1ab2

[12] Mydlo, J.H., Harris, C.F. and Brown, J.G. (2002) Blunt, Penetrating and Ischemic Injuries to the Penis. Journal of Urology, 168, 1433-1435. https://doi.org/10.1016/S0022-5347(05)64467-9

[13] Amit, A., Arun, K. and Behera, B. (2013) Penile Fracture and Associated Urethral Injury: Experience at a Tertiary Care Hospital. Canadian Urological Association Journal, 7, E168-E170. https://doi.org/10.5489/cuaj.475

[14] Kowalczyk, J., Athens, A. and Grimaldi, A. (1994) Penile Fracture: An Unusual Presentation with Lacerations of Bilateral Corpora Cavernosa and Partial Disruption of the Urethra. Urology, 44, 599-601. https://doi.org/10.1016/S0090-4295(94)80069-3

[15] Cumming, J. and Jenkins, J. (1991) Fracture of the Corpora Cavernosa and Urethral Rupture during Sexual Intercourse. British Journal of Urology, 67, 327. https://doi.org/10.1111/j.1464-410X.1991.tb15146.x

[16] Fergany, A.F., Angermeier, K.W. and Montague, D.K. (1999) Review of Cleveland Clinic Experience with Penile Fracture. Urology, 54, 352-355. https://doi.org/10.1016/S0090-4295(99)00115-6

[17] Phillips, E.A., Esposito, A.J. and Munarriz, R. (2015) Acute Penile Trauma and Associated Morbidity: 9-Year Experience at a Tertiary Care Center. Andrology, 3, 632-636. https://doi.org/10.1111/andr.12043

[18] Hoag, N.A., Hennessey, K. and So, A. (2011) Penile Fracture with Bilateral Corporeal Rupture and Complete Urethral Disruption: Case Report and Literature Review. Canadian Urological Association Journal, 5, E23-E26. https://doi.org/10.5489/cuaj.10055

[19] Yamaçake, K.G.R., Tavares, A. and Padovani, G.P. (2013) Long-Term Treatment Outcomes between Surgical Correction and Conservative Management for Penile Fracture: Retrospective Analysis. Korean Journal of Urology, 54, 472-476. https://doi.org/10.4111/kju.2013.54.7.472

[20] Mahapatra, R.S., Kundu, A.K. and Pal, D.K. (2015) Penile Fracture: Our Experience in a Tertiary Care Hospital. World Journal of Men's Health, 33, 95-102. https://doi.org/10.5534/wimh.2015.33.2.95

[21] Swanson, D.E.W., Polackwich, A.S. and Helfand, B.T. (2014) Penile Fracture: Outcomes of Early Surgical Intervention. Urology, 84, 1117-1121. https://doi.org/10.1016/j.urology.2014.07.034 
[22] Nicolaisen, G.S., Melamud, A., Williams, R.D. and McAninch, J.W. (1983) Rupture of the Corpus Cavernosum: Surgical Management. The Journal of Urology, 130, 917-919.

[23] Penson, D.F., Seftel, A.D., Krane, R.J., Frohrib, D. and Goldstein, I. (1992) The Hemodynamic Pathophysiology of Impotence Following Blunt Trauma to the Erect Penis. The Journal of Urology, 148, 1171-1180.

[24] Hatzichristodoulou, G., Dorstewitz, A., Gschwend, J.E., Herkommer, K. and Zantl, N. (2013) Surgical Management of Penile Fracture and Long-Term Outcome on Erectile Function and Voiding. The Journal of Sexual Medicine, 10, 1424-1430. https://doi.org/10.1111/jsm.12107

[25] Rivas, G.J., Dorrego, J.M.A. and Hernández, M.M. (2014) Traumatic Rupture of the Corpus Cavernosum: Surgical Management and Clinical Outcomes. A 30 Years Review. Central European Journal of Urology, 67, 88-92.

[26] Pavan, N., Tezzot, G., Liguori, G., et al. (2014) Penile Fracture: Retrospective Analysis of Our Case History with Long-Term Assessment of the Erectile and Sexological Outcome. Archivio Italiano di Urologia e Andrologia, 86, 359-370. https://doi.org/10.4081/aiua.2014.4.359

[27] Boncher, N.A., Vricella, G.J., Jankowski, J.T., Ponsky, L.E. and Cherullo, E.E. (2010) Penile Fracture with Associated Urethral Rupture. Case Reports in Medicine, 2010, Article ID: 791948. https://doi.org/10.1155/2010/791948

[28] Mensah, J.E., Morten, B. and Kyei, M. (2010) Early Surgical Repair of Penile Fractures. Ghana Medical Journal, 44, 119-122.

\section{Submit or recommend next manuscript to SCIRP and we will provide best service for you:}

Accepting pre-submission inquiries through Email, Facebook, LinkedIn, Twitter, etc. A wide selection of journals (inclusive of 9 subjects, more than 200 journals) Providing 24-hour high-quality service User-friendly online submission system Fair and swift peer-review system Efficient typesetting and proofreading procedure Display of the result of downloads and visits, as well as the number of cited articles Maximum dissemination of your research work

Submit your manuscript at: http://papersubmission.scirp.org/

Or contact oju@scirp.org 